\title{
Hausdorffen dimentsioa talde profinituetan
}

\author{
(Hausdorff dimension in profinite groups)
}

\author{
Iker de las Heras*, Andoni Zozaya** \\ Matematika Saila, Zientzia eta Teknologia Fakultatea (UPV/EHU)
}

LABURPENA: Hausdorffen dimentsioa eta kutxa-dimentsioa geometria fraktalaren esparruko oinarrizko kontzeptuak dira. Horiek ohiko dimentsio topologikoaren ideia orokortzen dute; izan ere, objektu geometriko arrunten dimentsioari ohiko balio bera ematen dieten bitartean, intuitiboki hain dimentsio argia ez duten zenbait multzo patologikori dimentsio ez oso bat esleitzen diote. Bestalde, azken hamarkadetan, Hausdorffen dimentsioaren kontzeptuak aplikazio emankor eta interesgarriak eman ditu oinarri zenbakigarriko talde profinituen testuinguruan, talde horiei espazio metriko egitura eman baitakieke. Artikulu honetan, alde batetik, Hausdorffen dimentsioaren eta kutxa-dimentsioaren teoriaren sarrera orokor bat egingo dugu. Beste alde batetik, Hausdorffen dimentsioak talde profinituetan eman dituen zenbait emaitza esanguratsu azalduko dira, arreta bi alor konkretutara bideratuz: Hausdorffen espektroa eta talde $R$-analitikoak.

HITZ GAKOAK: Fraktalak, kutxa-dimentsioa, Hausdorffen dimentsioa, talde profinituak, Hausdorffen espektroa, talde $R$-analitikoak.

ABSTRACT: The notions of Hausdorff dimension and box dimension are basic concepts in the field of fractal geometry. These concepts generalise the idea of the traditional topological dimension since, while the fractal dimension of a common geometric object coincides with the value of its typical dimension, certain pathological sets which, intuitively, do not have such a clear dimension, may have non-integer fractal dimension. In the last decades, the concept of Hausdorff dimension has provided fruitful and interesting applications in the context of countably based profinite groups, as these groups can always be seen as metric spaces. In this paper, on the one hand, we will give a general introduction to the theory of Hausdorff and box dimensions. On the other hand, we will see different significant results concerning Hausdorff dimension in profinite groups, focusing on two specific areas: the Hausdorff spectrum and R-analytic groups.

KEYWORDS: Fractals, box dimension, Hausdorff dimension, profinite groups, Hausdorff spectrum, R-analytic groups.

\footnotetext{
* Harremanetan jartzeko / Corresponding author: Iker de las Heras. Matematika Saila, Zientzia eta Teknologia Fakultatea, UPV/EHU, Sarriena auzoa, 48940 Leioa, Bizkaia. - iker.delasheras@ehu.eus - https://orcid.org/0000-0003-0275-1417

** Harremanetan jartzeko / Corresponding author: Andoni Zozaya. Matematika Saila, Zientzia eta Teknologia Fakultatea, UPV/EHU, Sarriena auzoa, 48940 Leioa, Bizkaia. - andoni.zozaya@ehu.eus - https://orcid.org/0000-0002-5342-4814

Nola aipatu / How to cite: De las Heras, Iker; Zozaya, Andoni (2021). «Hausdorffen dimentsioa talde profinituetan». Ekaia, 40, 2021, 291-314. (https://doi.org/10.1387/ekaia.21864).

Jasotze-data: 2020, ekainak 29; Onartze-data: 2021, urtarrilak 25.

ISSN 0214-9753 - eISSN 2444-3581 / (c) 2021 UPV/EHU
}

(i) (-) $\odot$ Lan hau Creative Commons Aitortu-EzKomertziala-LanEratorririkGabe 4.0 Nazioartekoa lizentzia baten mende dago 


\section{SARRERA}

Nahiz eta definizio formala emateko gai ez izan, guztiok dakigu figura geometriko sinple baten dimentsioa zein den. Esate baterako, senak esaten digu zuzen batek 1 dimentsioa duela eta plano batek, aldiz, 2 dimentsioa.

Figura geometriko baten dimentsioa intuitiboki puntu baten inguruan honek betetzen duen espazioa da, hau da, lokalki figura horren puntuak deskribatzeko eman beharreko koordenatu kopurua. Modu honetan, lokalki, zirkunferentzia zati bat zuzenki segmentu baten berdina denez, zati horretako puntu bakoitza zenbaki bakarrarekin identifika daiteke, eta, beraz, zirkunferentziak 1 dimentsioa du. Aldiz, disko batek lokalki plano guztia estaltzen du. Horrela, puntu bat deskribatzeko haren abzisa eta ordenatua eman behar direnez, diskoaren dimentsioa 2 da.

Horrela, bat erradioko diskoaren azalera finitua da, $\pi$ hain zuzen ere. Baina ez dauka zentzurik, intuitiboki hitz egiten, disko baten luzeraz -infinitua izango litzatekeena - edo bolumenaz -0 izango zena - hitz egiteak, horiek neurri unidimentsionala eta tridimentsionala baitira, hurrenez hurren. Aitzitik, bi dimentsioko objektu bornatu batek azalera finitu ez-nulua duenez, azalera neurri bidimentsionala dela onartzen dugu.

Modu berean, kurba leun batek 1 dimentsioa dauka, eta bornatua denean, luzera finitua. Haatik, kurba leuna ez denean, hau da, haren adierazpen grafikoak mutur zorrotzak dituenean, gauza patologikoak gerta daitezke. Adibidez, Peanoren kurbak plano guztia estaltzen du, eta, ondorioz, haren dimentsioa intuitiboki 2 izan beharko litzateke.


1. irudia. Peanoren kurba Giuseppe Peano matematikari italiarrak aurkeztu zuen 1890 ean. Haren grafoa $[0,1] \times[0,1] \subseteq \mathbb{R}^{2}$ karratua osorik estaltzen duen kurba jarraitua da. Hau jarraituak diren kurba familia baten limite uniformea da. Irudian, familia horretako zenbait kurbaren grafoak ikusten dira.

Edota, beste adibide bat ematearren, kontsideratu iteratiboki definituriko hurrengo eraikuntza. Izan bedi $V_{0}=[0,1]$, hots, $0 \leq x \leq 1$ betetzen duten zenbaki errealen multzoa. Halaber, $V_{1}$ eraikitzeko zatitu $[0,1]$ tartea luzera bereko hiru azpitartetan, ezabatu $(1 / 3,2 / 3)$ erdiko tartea, eta tarte horren ordez 
gehitu $V_{0}$-ri ezabatutako tartea oinarritzat duen hiruki aldekidearen beste bi aldeak. Modu honetan, $V_{1}$ kurba 1/3 luzerako 4 segmentuz osatutako figura geometrikoa da. Segmentu horietako bakoitzean errepikatu prozedura hori $V_{2}$ lortzeko. Modu honetan, $V_{2}$ kurba 1/9 luzerako 16 segmentuz osatuta dago. Urrats horiek errepikatuz $V_{n}$ kurba lor daiteke edozein $n$ zenbaki arrunterako.
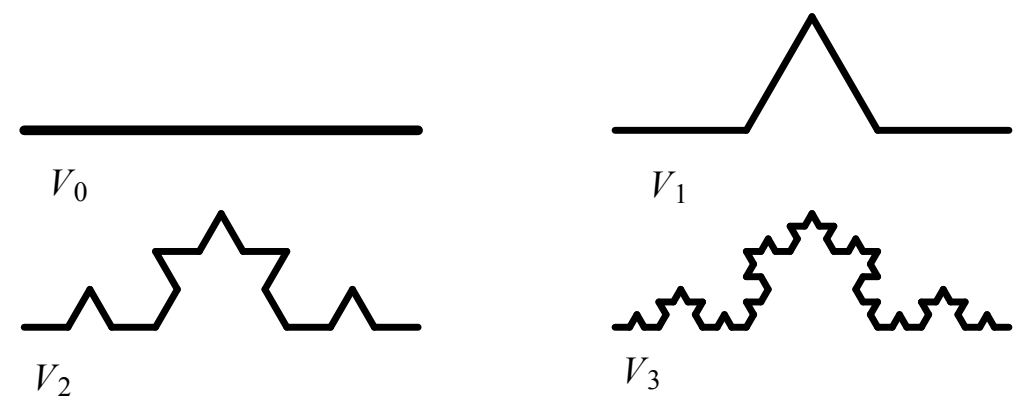

2. irudia. Aurreko eraikuntzako lehen lau urratsak.

Prozesu hori infinitu aldiz errepikatuz, hau da, $V_{n}$ kurben «limitea hartuz», von Kochen kurba, deitu $V$, erdiesten da, Helge von Kochek 1904an aurkeztu zuena. Urrats bakoitzean $V_{n}$ kurbak $1 / 3^{n}$ luzerako $4^{n}$ segmentu dituenez, $(4 / 3)^{n}$ luzera dauka. Ondorioz, nahiz eta $V$ kurba bornatua izan, von Kochen kurbak luzera infinitua du. Baina Peanoren kurbak ez bezala, ez du plano guztia estaltzen, eta, ondorioz, haren azalera 0 da. Beraz, von Kochen kurbak 1 eta 2 arteko dimentsioa izan beharko luke, ohiko dimentsio euklidearra beti osoa izan arren.

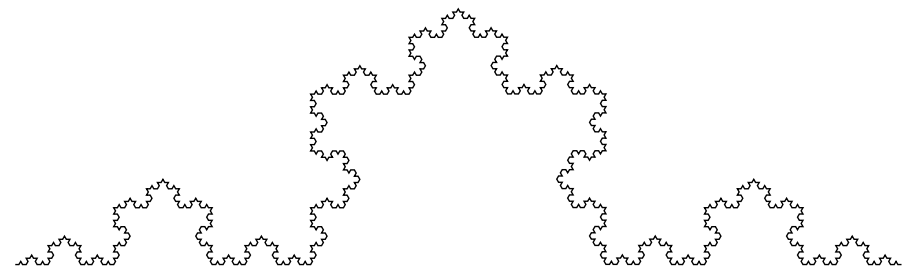

3. irudia. Limite bat denez, ezinezkoa da von Kochen kurba irudikatzea. Oro har, kurbaren gutxi gorabeherako itxura irudikatzeko, $V_{n}$ bat marraztu ohi da, $n$ handi baterako.

Aurreko adibideek erakusten dute beharrezkoa dela dimentsio topologikoaren kontzeptua orokortzea, eta zenbait figura geometrikok dimentsio ez-osoa izan beharko luketela. Von Kochen kurba kurba fraktala da; izen hori 1975ean proposatu zuen Benoît Mandelbrotek, aurreko mendeetan zehar hainbat matematikarik irudi mota haien inguruan egindako lana bil- 
tzeko. Fraktal izena latineko fractus-etik dator, zeinak «hautsia» edo «apurtua» esan nahi duen. Izenak adierazten duen moduan, fraktalak itxuraz irregularrak diren eta zatituta dauden figura geometrikoak dira, baina benetan haien oinarrizko forma behin eta berriz errepikatzen da eskala ezberdinetan. Horrela, errepikapena aldiro konstantea izan daiteke, von Kochen kurban bezala, edo ausazko faktore baten bidez erabakitakoa.

Formalki, fraktalak beren dimentsio fraktala dimentsio topologikoa baino hertsiki handiagoa duten forma geometrikoak dira. Aitzitik, arazo nagusia da ez dagoela dimentsio fraktala definitzeko modu bakarra.

\section{KUTXA-DIMENTSIOA}

Dimentsio fraktal sinple eta erabilgarrienetariko bat kutxa-dimentsioa edo Minkowski-Bouliganden dimentsioa da, batik bat 1930eko hamarkadan aztertzen hasi zirena. Kutxa-dimentsioa modu honetan definitzen da $(M, d)$ espazio metriko batean (ikusi $[1,2$. gaia]): $X \subseteq M$ azpimultzo baten diametroa bata bestearengandik urrunen dauden $X$-ko puntuen arteko distantzia da, hau da,

$$
\operatorname{diam}(X):=\sup \{d(x, y) \mid x, y \in X\} .
$$

Halaber, edozein $\delta$ positibotarako, $X$-ren $\left\{U_{i}\right\}_{i \in \mathbb{N}}$ estalki zenbakigarri edo finitu bat $\delta$-estalki deitzen da $\operatorname{diam}\left(U_{i}\right)$ gehienez $\delta$ denean $i \in \mathbb{N}$ guztietarako. Izan bedi $N_{\delta}(X)$ zenbakia $X$ multzoa estaltzeko beharrezkoa den gehienez $\delta$ diametroko gutxieneko azpimultzo kopurua, hau da, $\delta$-estalkien kardinalen beherena.

Adibidez, $C$ kurba leun bornatu baten kasuan gutxi gorabehera $N_{\delta}(C) \approx c \delta^{-1}$ betetzen da, $c$ konstante batentzat, edota $P$ poligono baten barnealdearentzat $N_{\delta}(P) \approx c \delta^{-2}$ da. Hori orokortuz, $X$ multzoak $N_{\delta}(X) \approx c \delta^{-s}$ betetzen badu $s \geq 0$-ren batentzat, orduan $s$ bere dimentsio fraktala dela esango dugu.

Logaritmoak hartuz $\log N_{\delta}(X) \approx \log c-s \log \delta$ dugu, eta, ondorioz,

$$
s=\lim _{\delta \rightarrow 0} \frac{\log N_{\delta}(X)}{-\log \delta}
$$

formula erdiesten dugu. Hala ere, gerta daiteke aurreko limitea ez existitzea, eta, hortaz, existentzia bermatzearren, limite beherena edota limite gorena hartu behar ditugu.

Definizioa 2.1. Izan bitez $(M, d)$ espazio metrikoa eta $X \subseteq M$. Orduan, behe kutxa-dimentsioa eta goi kutxa-dimentsioa honako hauek dira, hurrenez hurren: 
(i) $\underline{\operatorname{dim}}_{\mathrm{B}}(X):=\liminf _{\delta \rightarrow 0} \frac{\log N_{\delta}(X)}{-\log \delta}$.

(ii) $\overline{\operatorname{dim}}_{\mathrm{B}}(X):=\limsup \sup _{\delta \rightarrow 0} \frac{\log N_{\delta}(X)}{-\log \delta}$.

Bi limite horiek bat datozenean, balio komun horri $X$-ren kutxa-dimentsioa deritzo, $\operatorname{dim}_{\mathrm{B}}(X)$ idazten dena.

Nahiz eta $N_{\delta}$-ren definizioan $\delta$ diametroko edozein estalki onartzen den, balio bera lortzen da soilik $\delta$ diametroko bolak edo $\mathbb{R}^{n}$-ren kasuan kutxak hartzen badira. Hots, azpimultzoa geroz eta kutxa txikiagoen bidez hurbiltzen da, eta kutxa bakoitzean azpimultzoak betetzen duen espazioa zein den kalkulatzen da. Horrek justifikatzen du kutxa-dimentsio izena.

Adibidea 2.2 (von Kochen kurbaren kutxa-dimentsioa). Ikus dezagun von Kochen kurbarako $\operatorname{dim}_{\mathrm{B}} V=\log 4 / \log 3$ dela. Alegia, espero moduan $\operatorname{dim}_{B} V \approx 1.26$ dimentsio fraktala 1 eta 2 artean dagoen zenbaki erreal ez-osoa da. Alde batetik, ikusi dugu $V_{n}$ urratsa $3^{-n}$ luzerako $4^{n}$ segmentuk osatzen dutela; beraz, $3^{-n} \leq \delta \leq 3^{-n+1}$ denean, $N_{\delta}(V) \leq 4^{n}$ da eta ondorioz

$$
\overline{\operatorname{dim}}_{\mathrm{B}}(V)=\limsup _{\delta \rightarrow 0} \frac{\log N_{\delta}(V)}{-\log \delta} \leq \lim _{n \rightarrow \infty} \frac{\log 4^{n}}{-\log 3^{-n+1}}=\lim _{n \rightarrow \infty} \frac{n \log 4}{(n-1) \log 3}=\frac{\log 4}{\log 3} .
$$

Bestalde, $3^{-n-1} \leq \delta<3^{-n}$ bada, $\delta$ diametroko bola batek ez du $V_{n}$ osatzen duten segmentuetako bakarra ere osorik estaltzen. Ondorioz, segmentu bakoitza estaltzeko gutxienez bi bola behar dira, eta $V_{n}$-n horrelako $4^{n}$ segmentu daudenez, erraz ikusten da $N_{\delta}(V)$ gutxienez $4^{n}$ dela. Hortaz,

$$
\underline{\operatorname{dim}}_{\mathrm{B}}(V)=\liminf _{\delta \rightarrow 0} \frac{\log N_{\delta}(V)}{-\log \delta} \geq \lim _{n \rightarrow \infty} \frac{\log 4^{n}}{-\log 3^{-n-1}}=\frac{\log 4}{\log 3},
$$

beste desberdintza lortuz.

Nolanahi ere, kutxa-dimentsioak arazo bat du: gerta daiteke zenbait multzo txikik - multzo zenbakigarriak - dimentsio ez-nulua izatea. $\mathrm{Hu}$ rrengo emaitzan oinarritzen da arazo hori.

Lema 2.3 (ikusi [1, Proposizioa 2.6]). Izan bitez $(M, d)$ espazio metrikoa, $X \subseteq M$ multzoa eta $\bar{X}$ bere itxitura. Orduan,

$$
\underline{\operatorname{dim}}_{\mathrm{B}}(X)=\underline{\operatorname{dim}}_{\mathrm{B}}(\bar{X}) \quad \text { eta } \quad \overline{\operatorname{dim}}_{\mathrm{B}}(X)=\overline{\operatorname{dim}}_{\mathrm{B}}(\bar{X}) .
$$


Frogapena. Izan bedi $\mathcal{B}=\left\{B_{i}\right\}_{i=1}^{n}$ gehienez $\delta$ diametroko bola itxi familia finitua. Orduan, $\mathcal{B}$-k $X$ estaltzen du baldin eta soilik baldin $\bar{X}$ estaltzen badu. Beraz, kutxa-dimentsioaren kalkuluan $\delta$-estalki itxiak bakarrik hartzea nahikoa denez, emaitza berehalakoa da.

Ondorioz, $\mathbb{R}$-ko ohiko metrikarekin $X=\mathbb{Q} \cap[0,1]$ multzoa $[0,1]$ tartean dentsoa denez, $\operatorname{dim}_{\mathrm{B}}(X)=\operatorname{dim}_{\mathrm{B}}([0,1])=1 \mathrm{da}$, nahiz eta $X$ multzo zenbakigarria izan. Arazo honen oinarrian $N_{\delta}$-ren batukortasun zenbakigarri falta dago, hau da, $N_{\delta}$ ez da neurri bat. Ondorioz, nahiz eta kutxa-dimentsioa kalkulatzeko erosoa eta ulerterraza izan, neurri egitura eza dela eta, ez da formalki lan egiteko dimentsio fraktal egokiena.

\section{HAUSDORFFEN DIMENTSIOA}

Aipatu dugunez dimentsio fraktal anitz defini daitezke, eta sinpleenetariko bat izan arren, kutxa-dimentsioak zenbait desabantaila ditu. Dimentsio fraktalen artean zaharrenetariko bat Hausdorffen dimentsioa da. Dimentsio hori hasiera batean espazio euklidearretan aztertu bazen ere, edozein espazio metrikotan defini daiteke, eta haren abantaila nagusia da neurri bati lotuta dagoela. Oro har, multzo askotan bere balioa kutxa-dimentsioaren balioarekin bat dator, baina zenbaitetan ezberdinak izan daitezke.

Atal honetan batik bat $[1,3$. gaia] jarraituko da. Izan bitez $(M, d)$ espazio metrikoa eta $X \subseteq M$ multzoa. Definitu

$$
\mathcal{H}_{\delta}^{s}(X):=\inf \left\{\sum_{i=1}^{\infty} \operatorname{diam}\left(U_{i}\right)^{s} \mid\left\{U_{i}\right\}_{i \in \mathbb{N}} X \text {-ren } \delta \text {-estalkia da }\right\} .
$$

Modu argian, $\delta$ txikitu ahala balizko estalki gutxiago daude, eta, beraz, $\mathcal{H}_{\delta}^{s}$ monotono ez-beherakorra da. Hortaz, bere limitea har daiteke:

$$
\mathcal{H}^{s}(X):=\lim _{\delta \rightarrow 0} \mathcal{H}_{\delta}^{s}(X),
$$

zeinak askotan infinitu balioa har dezakeen. Ikus daiteke $\mathcal{H}^{s}$ neurri bat dela multzo irekiek sortutako Borelen $\sigma$-aljebran, Hausdorffen s-neurri deitutakoa (ikusi [2, Proposizioa 11.17]). Adibidez, erraz ikusten da $\mathcal{H}^{0}(X)$ multzoaren puntu kopurua dela. Halaber, $\mathbb{R}^{n}$-n $s=1$, 2 edo 3 denean $\mathcal{H}^{s}$, hurrenez hurren ohiko luzera, azalera edo bolumen kontzeptuekin bat dator, konstante bat salbu balio bera hartzen baitute. Zehazki, $X$ Borelen azpimultzoa denean

$$
\mathcal{H}^{s}(X)=c_{s}^{-1} \operatorname{bol}_{s}(X)
$$




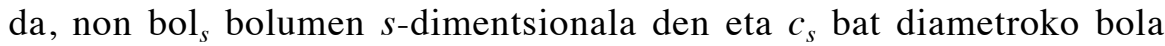
$s$-dimentsionalaren bolumena den (ikusi [1, Atala 3.1]). Bereziki, $X$ kurba leuna denean $\mathcal{H}^{1}(X)$ bere luzera da, edo $X$ gainazal leuna denean $\mathcal{H}^{2}(X)=4 / \pi \cdot \operatorname{azal}(X)$ da.

Lema 3.1. Demagun $\mathcal{H}^{s}(X)<\infty$ dela, eta izan bedi $s<t$. Orduan, $\mathcal{H}^{t}(X)=0 d a$.

Frogapena. Izan bedi $\left\{U_{i}\right\}_{i \in \mathbb{N}} X$-ren $\delta$-estalki bat. Orduan,

$$
\sum_{i=1}^{\infty} \operatorname{diam}\left(U_{i}\right)^{t}=\sum_{i=1}^{\infty} \operatorname{diam}\left(U_{i}\right)^{t-s} \operatorname{diam}\left(U_{i}\right)^{s} \leq \delta^{t-s} \sum_{i=1}^{\infty} \operatorname{diam}\left(U_{i}\right)^{s} .
$$

Ondorioz, beherenak hartuta $\mathcal{H}_{\delta}^{t}(X) \leq \delta^{t-s} \mathcal{H}_{\delta}^{s}(X)$, eta, beraz,

$$
\mathcal{H}^{t}(X)=\lim _{\delta \rightarrow 0} \mathcal{H}_{\delta}^{t}(X) \leq \lim _{\delta \rightarrow 0} \delta^{t-s} \mathcal{H}_{\delta}^{s}(X)=0,
$$

nahi genuen moduan.

Modu honetan, $s$-rekiko $\mathcal{H}^{s}(X)$-ren grafikoa marraztuz gero, $s$-ren balio kritiko bateraino honek infinitu balio duela eta hortik aurrera 0 balioa hartzen duela ikusten da.



4. irudia. $X$ multzo baterako $\mathcal{H}^{s}(X)$-ren bilakaera $s$-rekiko.

Balio hori da hain zuzen ere $X$ multzoaren Hausdorffen dimentsioa, $\operatorname{hdim}(X)$ moduan denotatuko dena. Alegia,

$$
\operatorname{hdim}(X):=\sup \left\{s \mid \mathcal{H}^{s}(X)=\infty\right\}=\inf \left\{s \mid \mathcal{H}^{s}(X)=0\right\} .
$$


Multzoaren Hausdorffen dimentsioa $s$ bada, $\mathcal{H}^{s}(X)$ infinitu, 0 edo beste zenbaki erreal bat izan daiteke. Haatik,

$$
0<\mathcal{H}^{s}(X)<\infty
$$

bada, $s=\operatorname{hdim}(X)$ da. Honek zenbaitetan Hausdorffen dimentsioa kalkulatzeko balio dezake. Adibidez, hartu $\mathbb{R}^{2}$ espazio metrikoan 1 erradioko $\mathbb{D}$ diskoa. Orduan, arestian aipatu bezala, $\mathcal{H}^{2}(\mathbb{D})=4 / \pi \cdot \operatorname{azal}(\mathbb{D})=4$ da, eta ondorioz, $\operatorname{hdim}(\mathbb{D})=2$ da.

Propietateak 3.2. Hausdorffen dimentsioaren propietate nagusiak honako hauek dira:

(i) Monotonia: $Y \subseteq X$ bada, orduan $\operatorname{hdim}(Y) \leq \operatorname{hdim}(X)$ da.

(ii) Egonkortasun zenbakigarria: $\left\{X_{n}\right\}_{n \in \mathbb{N}}$ multzo familia zenbakigarria bada, orduan

$$
\operatorname{hdim}\left(\bigcup_{n \in \mathbb{N}} X_{n}\right)=\operatorname{suphdim}_{n \in \mathbb{N}}\left(X_{n}\right) .
$$

(iii) Multzo zenbakigarrien dimentsioa: $X$ multzo zenbakigarria bada, orduan $\operatorname{hdim}(X)=0$ da.

Frogapena. (i) Ohartu $\left\{U_{i}\right\}_{i \in \mathbb{N}} X$-ren $\delta$-estalkia bada, orduan $Y$-ren $\delta$-estalkia ere badela. Beraz, $H_{\delta}^{s}(Y) \leq H_{\delta}^{s}(X)$ da $s \in \mathbb{R}_{\geq 0}$ guztietarako.

(ii) Alde batetik, monotoniagatik $\operatorname{hdim}\left(\cup_{n \in \mathbb{N}} X_{n}\right) \geq \operatorname{hdim}\left(X_{i}\right)$ da $i \in \mathbb{N}$ guztietarako. Bestetik, $\operatorname{hdim}\left(X_{n}\right)<s$ bada $n \in \mathbb{N}$ guztietarako, orduan $\mathcal{H}^{s}\left(X_{n}\right)=0$ da $n \in \mathbb{N}$ guztietarako, eta, hortaz, $\mathcal{H}^{s}\left(\cup_{n \in \mathbb{N}} X_{n}\right) \leq \sum_{n \in \mathbb{N}} \mathcal{H}^{s}\left(X_{n}\right)=0$. Beraz, $\operatorname{hdim}\left(\cup_{n \in \mathbb{N}} X_{n}\right)<s$ da, eta emaitza berehalakoa da.

(iii) Lehenik $\mathcal{H}^{0}$ zenbaketa-neurria denez, $\mathcal{H}^{0}(\{x\})=1$ da, eta, beraz, $\operatorname{hdim}(\{x\})=0$ da $x \in X$ guztietarako. Egonkortasun zenbakigarriagatik

$$
\operatorname{hdim}(X)=\operatorname{hdim}\left(\bigcup_{x \in X}\{x\}\right)=\sup _{x \in X} \operatorname{hdim}(\{x\})=0,
$$

nahi genuen moduan.

Interesgarria da Hausdorffen dimentsioaren eta aurreko atalean aztertutako kutxa-dimentsioaren arteko erlazioa aztertzea.

Teorema 3.3 (ikusi [1, Proposizioa 3.4]). Edozein X multzotarako

$$
\operatorname{hdim}(X) \leq \underline{\operatorname{dim}}_{\mathrm{B}}(X) \leq \overline{\operatorname{dim}}_{\mathrm{B}}(X) .
$$


Frogapena. Bigarren desberdintza nabaria da. Lehenengorako, ohartu $X$ finitua denean bi aldeek zero balio dutela. Bestelakoan, hartu $s \geq 0$, non

$$
1<\mathcal{H}^{s}(X)=\lim _{\delta \rightarrow 0} \mathcal{H}_{\delta}^{s}(X)
$$

den. Bereziki $\delta$ behar bezain txikirako $1<\mathcal{H}_{\delta}^{s}(X)$ da. Bestalde, $N_{\delta}(X) X$-ren $\delta$-estalkien kardinalen beherena denez

$$
1<\mathcal{H}_{\delta}^{s}(X)=\inf \left\{\sum_{i=1}^{\infty} \operatorname{diam}\left(U_{i}\right)^{s} \mid\left\{U_{i}\right\}_{i \in \mathbb{N}} \delta \text {-estalkia da }\right\} \leq N_{\delta}(X) \delta^{s}
$$

da. Beraz, logaritmoak hartuz $0<\log N_{\delta}(X)+s \log \delta$ da, eta $\delta$ behar bezain txikirako - $\log \delta$ positiboa dela eman dezakegunez

$$
s \leq \liminf _{\delta \rightarrow 0} \frac{\log N_{\delta}(X)}{-\log \delta}=\underline{\operatorname{dim}}_{\mathrm{B}}(X),
$$

eta, beraz,

$$
\operatorname{hdim}(X)=\sup \left\{s \mid \mathcal{H}^{s}(X)=\infty\right\} \leq \underline{\operatorname{dim}}_{\mathrm{B}}(X),
$$

lehen desberdintza ere frogatuz.

Zenbait kasu interesgarritan desberdintza horiek hertsiak izan daitezke. Esate baterako, $X \subseteq M$ multzo zenbakigarri dentsoa bada (adibidez, $X=\mathbb{Q} \cap[0,1]$ multzoa [0,1]-n ohiko metrikarekin) Lema 2.3-ren ondorioz bere kutxa-dimentsioa $\operatorname{dim}_{\mathrm{B}}(X)=\operatorname{dim}_{\mathrm{B}}(M)$ da, baina Propietateak 3.2(iii) dela eta, $\operatorname{hdim}(X)=0$ da.

\section{TALDE PROFINITUAK}

Esan bezala, Hausdorffen dimentsioa edozein espazio metrikotan azter daiteke. Guk espazio metriko berezi batean jarriko dugu arreta, talde profinituetan, alegia.

Definizioa 4.1. Talde profinitu bat talde topologiko Hausdorff eta trinko bat da, non azpitalde normal irekiek identitatearen ingurune oinarri bat osatzen duten.

Azterketak interesa izan dezan, gure taldeak oinarri zenbakigarriko (azpitalde ireki normal kantitate zenbakigarria dute) talde profinitu infinituak izango dira. Azpitalde normal irekiek identitatearen ingurune oinarri bat 
osatzen dutenez, oinarri zenbakigarriko talde profinituetan filtrazio serieak topa daitezke. Hau da, $\mathcal{G}=\left(G_{n}\right)_{n \in \mathbb{N}}$ azpitalde irekien familia beherakor bat,

$$
G=G_{0} \supseteq G_{1} \supseteq \cdots \supseteq G_{n} \supseteq \cdots,
$$

non $\cap_{n \in \mathbb{N}} G_{n}=\{1\}$ den. Halaber, filtrazioa normala dela esaten da $G_{n}$ azpitalde guztiak normalak direnean.

Ohartu $H \leq G$ azpitaldea irekia denean, $|G: H|$ finitua dela. Izan ere, $H$ irekia denean $\{g H\}_{g \in G}$ ezker-koklaseek $G$-ren estalki ireki bat osatzen dute, eta trinkotasunagatik estalki horrek finitua izan behar du. Bereziki, filtrazioko azpitalde guztiek indize finitua dute $G$-n. Hortaz, filtrazio serie bat erabilita, honako funtzio honek $G$-n metrika bat definitzen du:

$$
d^{\mathcal{G}}(x, y):=\inf \left\{\left|G: G_{n}\right|^{-1} \mid x y^{-1} \in G_{n}\right\} .
$$

Oharra. Aurreko distantziaren notazioan $\mathcal{G}$ filtrazioa zein den esplizituki adierazi da, taldearen metrika filtrazio serie horrek definitzen duena dela azpimarratzeko. Berdin, aitzinago $\operatorname{dim}_{\mathrm{B}}^{\mathcal{G}}$ edo hdim ${ }^{\mathcal{G}}$ notazioak erabiliko dira, hurrenez hurren, kutxa-dimentsioa eta Hausdorffen dimentsioa metrika horrekiko kalkulatu direla azpimarratzeko.

Metrika honetan $x \in G$ eta $\delta=\left|G: G_{n}\right|^{-1}$ badira, orduan $x$ zentroko eta $\delta$ erradioko $B(x, \delta)$ bola $x G_{n}$ koklasea besterik ez da. Beraz, $x \equiv y$ $\left(\bmod G_{n}\right)$ bada, $B(x, \delta)=B(y, \delta)$ da; ondorioz, $B(x, \delta)$ bolak $\delta$ diametroa du eta $\delta$ diametroko $\left|G: G_{n}\right|$ bola baino ez daude. Hortaz, $N_{\delta}(H), H$ estaltzeko beharrezkoa den gehienez $\delta$ diametroko gutxieneko bola kopurua, $\left|\left\{x G_{n} \mid x \in H\right\}\right|$ koklase kopurua da, hau da, filtrazio seriea normala denean, $N_{\delta}(H)=\left|H G_{n}: G_{n}\right|=\left|H: H \cap G_{n}\right|$ da. Bestalde, $n$ handitu ahala $\delta=\left|G: G_{n}\right|^{-1}$ txikitu egiten denez,

$$
\underline{\operatorname{dim}}_{B}^{\mathcal{G}}(H)=\liminf _{\delta \rightarrow 0} \frac{\log N_{\delta}(H)}{-\log \delta}=\liminf _{n \rightarrow \infty} \frac{\log \left|H G_{n}: G_{n}\right|}{\log \left|G: G_{n}\right|} .
$$

Halaber, Abercombriek (ikusi [3]) frogatu zuenaren arabera, filtrazio seriea normala denean, talde profinituetan azpitalde itxi baten Hausdorffen dimentsioa eta behe kutxa-dimentsioa bat datoz. Laburbilduz, honako hau dugu:

Teorema 4.2 (ikusi [4, Teorema 2.4]). Izan bitez $G$ talde profinitua eta $\mathcal{G}=\left(G_{n}\right)_{n \in \mathbb{N}}$ filtrazio serie normala. Orduan, $H \leq G$ itxi guztietarako

$$
\operatorname{hdim}^{\mathcal{G}}(H)=\liminf _{n \rightarrow \infty} \frac{\log \left|H G_{n}: G_{n}\right|}{\log \left|G: G_{n}\right|}=\liminf _{n \rightarrow \infty} \frac{\log \left|H: H \cap G_{n}\right|}{\log \left|G: G_{n}\right|} \in[0,1]
$$

$d a$. 
Hori dela eta, kontrakorik esan ezean, hemendik aurrera filtrazio serieak normalak direla joko dugu.

Adibideak 4.3. Zenbait azpitalderentzat Hausdorffen dimentsioa kalkulatzea erraza da.

(i) Alde batetik, Propietateak 3.2-n ikusi dugu azpimultzo zenbakigarri guztiek zero dimentsioa daukatela. Dena den, talde profinitu baten azpitalde bat zenbakigarria bada, orduan finitua da, eta azpitalde finitu batek dimentsio nulua duela zuzenean froga daiteke (1) erabilita. Izan ere, $H \leq G$ finitua bada, filtrazio seriea beherakorra denez $H \cap G_{n}=\{1\}$ da $n$ behar bezain handi baterako eta, beraz,

$$
\operatorname{hdim}^{\mathcal{G}}(H)=\liminf _{n \rightarrow \infty} \frac{\log \left|H: H \cap G_{n}\right|}{\log \left|G: G_{n}\right|}=|H| \liminf _{n \rightarrow \infty} \frac{1}{\left|G: G_{n}\right|}=0 .
$$

(ii) Berehalakoa da $\operatorname{hdim}^{\mathcal{G}}(G)=1$ dela ikustea. Orokorrean $H \leq G$ azpitalde irekia bada, orduan $\operatorname{hdim}^{\mathcal{G}}(H)=1$ da. Izan ere, $H \leq G$ irekia denean $|G: H|$ finitua da, eta, ondorioz,

$$
\begin{aligned}
\operatorname{hdim}^{\mathcal{G}}(H) & =\liminf _{n \rightarrow \infty} \frac{\log \left|H G_{n}: G_{n}\right|}{\log \left|G: G_{n}\right|}=\liminf _{n \rightarrow \infty} \frac{\log \left|G: G_{n}\right|-\log \left|G: H G_{n}\right|}{\log \left|G: G_{n}\right|} \\
& =1-\limsup _{n \rightarrow \infty} \frac{\log \left|G: H G_{n}\right|}{\log \left|G: G_{n}\right|} \geq 1-\limsup _{n \rightarrow \infty} \frac{\log |G: H|}{\log \left|G: G_{n}\right|}=1 .
\end{aligned}
$$

Filtrazio serie guztiek topologia bera definitzen badute ere, metrikak eta, beraz, Hausdorffen dimentsioak hartzen dituen balioak filtrazioaren menpekoak dira. Hurrengo adibidearen bidez ikus daiteke egoera hau.

Adibideak 4.4. (ikusi [4, Adibidea 2.5]). Izan bitez, $p$ zenbaki lehen baterako, $G=\mathbb{Z}_{p} \oplus \mathbb{Z}_{p}$ zenbaki oso $p$-adikoen bi kopiak definitutako talde profinitu batukorra eta $H=\mathbb{Z}_{p} \oplus\{0\}$ azpitalde itxia.

(i) Hartu $\mathcal{G}=\left(G_{n}\right)_{n \in \mathbb{N}}$ filtrazio seriea, non $G_{n}=p^{n} \mathbb{Z}_{p} \oplus p^{n} \mathbb{Z}_{p}$ den. Orduan,

$$
\begin{aligned}
& \left|G: G_{n}\right|=\left|\mathbb{Z}_{p} / p^{n} \mathbb{Z}_{p} \oplus \mathbb{Z}_{p} / p^{n} \mathbb{Z}_{p}\right|=\left|\mathbb{Z} / p^{n} \mathbb{Z} \oplus \mathbb{Z} / p^{n} \mathbb{Z}\right|=p^{2 n} \\
& \text { eta } \\
& \left|H: H \cap G_{n}\right|=\left|\mathbb{Z}_{p} \oplus\{0\}: p^{n} \mathbb{Z}_{p} \oplus\{0\}\right|=\left|\mathbb{Z}_{p} / p^{n} \mathbb{Z}_{p}\right|=\left|\mathbb{Z} / p^{n} \mathbb{Z}\right|=p^{n} \\
& \text { dira, eta, ondorioz, } \operatorname{hdim}^{\mathcal{G}}(H)=1 / 2 \text { da. }
\end{aligned}
$$






5. irudia. Lehen hiru $n$-etarako, $H G_{n} / G_{n}$-k $G / G_{n} \cong \mathbb{Z}_{p} / p^{n} \mathbb{Z}_{p} \oplus \mathbb{Z}_{p} / p^{n} \mathbb{Z}_{p}$-n betetzen duen indizearen proportzio logaritmikoa belztuta ageri da.

(ii) Hartu $\mathcal{S}=\left(S_{n}\right)_{n \in \mathbb{N}}$ filtrazio seriea, non $S_{n}=p^{2 n} \mathbb{Z}_{p} \oplus p^{n} \mathbb{Z}_{p}$ den. Orduan,

$$
\operatorname{hdim}^{\mathcal{S}}(H)=\liminf _{n \rightarrow \infty} \frac{\log \left|H S_{n}: S_{n}\right|}{\log \left|G: S_{n}\right|}=\liminf _{n \rightarrow \infty} \frac{2 n}{3 n}=\frac{2}{3} .
$$

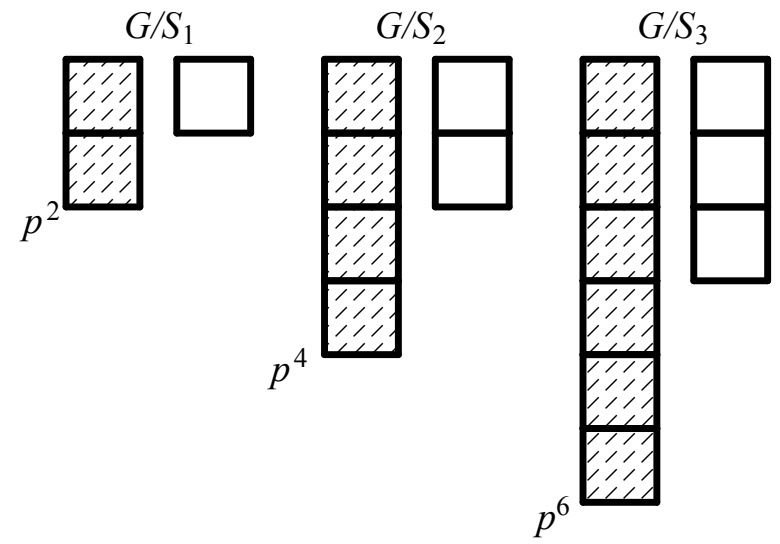

6. irudia. 5. irudiaren analogoa $\mathcal{S}$ filtrazio serierako.

Modu berean, ikus daiteke $S_{n}=p^{n} \mathbb{Z}_{p} \oplus p^{2 n} \mathbb{Z}_{p}$ bada, $\operatorname{hdim}^{\mathcal{S}}(H)=1 / 3$ dela.

(iii) Hartu $\mathcal{T}=\left(T_{n}\right)_{n \in \mathbb{N}}$ filtrazio seriea, non $T_{n}=p^{n^{2}} \mathbb{Z}_{p} \oplus p^{n} \mathbb{Z}_{p}$ den. Orduan,

$$
\operatorname{hdim}^{\mathcal{T}}(H)=\liminf _{n \rightarrow \infty} \frac{\log \left|H T_{n}: T_{n}\right|}{\log \left|G: T_{n}\right|}=\liminf _{n \rightarrow \infty} \frac{n^{2}}{n^{2}+n}=1
$$

da, nahiz eta $H$ indize infinituko azpitaldea izan. 


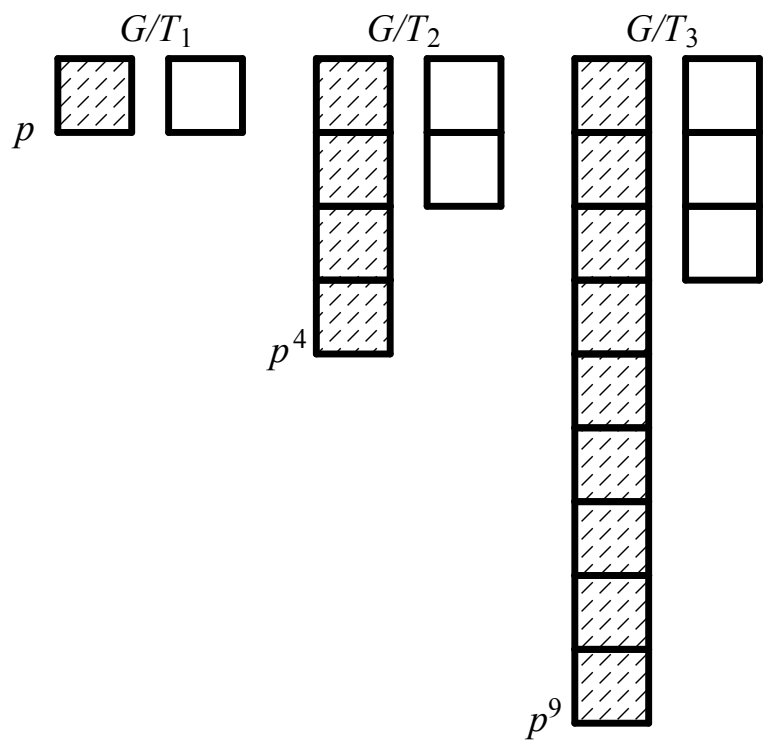

7. irudia. 5. irudiaren analogoa $\mathcal{T}$ filtrazio serierako.

Modu analogoan, $T_{n}=p^{n} \mathbb{Z}_{p} \oplus p^{n^{2}} \mathbb{Z}_{p}$ bada, $\operatorname{hdim}^{\mathcal{T}}(H)=0$ da, $H$ azpitalde finitua izan ez arren.

Nahiz eta oinarri zenbakigarriko talde profinitu batean beti topa daitekeen filtrazio serie bat, horietako batzuk oso patologikoak izan daitezke. Badira, ordea, talde profinituen teorian modu naturalean azaltzen diren eta taldearen informazio estruktural ugari gordetzen duten filtrazio serieak (gogoratu pro- $p$ talde bat talde profinitu bat dela, non azpitalde normal ireki guztien indizea $p$-ren berretura bat den).

Adibideak 4.5. Izan bedi $p$ zenbaki lehen bat. Finituki sortutako pro- $p$ taldeetan zenbait filtrazio serie natural daude. Besteak beste, hauek:

- P: p-berretura seriea: $\pi_{i}(G)=G^{p^{i}}=\left\langle x^{p^{i}} \mid x \in G\right\rangle$, edozein $i \geq 0$-tarako;

- $\mathcal{P}^{*}$ : p-berretura serie iteratua: $\pi_{0}^{*}(G)=G$ eta $\pi_{i}^{*}(G)=\pi_{i-1}^{*}(G)^{p}$, edozein $i \geq 1$-tarako;

- $\mathcal{L}$ : Serie p-zentral beherakorra: $P_{1}(G)=G$ eta $P_{i}(G)=$ $P_{i-1}(G)^{p}\left[P_{i-1}(G), G\right]$, edozein $i \geq 2$-tarako;

$-\mathcal{F}$ : Frattini seriea: $\Phi_{0}(G)=G$ eta

$$
\Phi_{i}(G)=\Phi_{i-1}(G)^{p}\left[\Phi_{i-1}(G), \Phi_{i-1}(G)\right],
$$

edozein $i \geq 1$-tarako; 
$-\mathcal{D}$ : Dimentsio azpitalde seriea: $D_{1}(G)=G$ eta

$$
D_{i}(G)=D_{\lceil i / p\rceil}(G)^{p} \prod_{1 \leq j<i}\left[D_{j}(G), D_{i-j}(G)\right],
$$

edozein $i \geq 2$-tarako.

Ohartu filtrazio serie horiek guztiak normalak direla. Bestalde, nahiz eta serie horiek edozein pro- $p$ taldetan defini daitezkeen, taldea finituki sortua ez denean, gerta daiteke serieetako azpitaldeak irekiak ez izatea.

\section{HAUSDORFFEN ESPEKTROA ETA ESPEKTRO NORMALA}

Izan bitez $G$ talde profinitua eta $\mathcal{G}$ filtrazio seriea. Ikusi dugunez, $\mathcal{G}$ normala bada, Teorema 4.2-ko formulak $G$-ren azpitalde itxien Hausdorffen dimentsioa kalkulatzea ahalbidetzen du. Guztiz naturala da, ondorioz, $G$ talde profinituaren azpitalde itxien dimentsioek har ditzaketen balioak zein diren aztertzea. Ildo horri jarraituz, honako hau defini daiteke.

Definizioa 5.1. Izan bitez $G$ talde profinitua eta $\mathcal{G}$ filtrazio seriea. Orduan, $G$ filtrazioari dagokion $G$-ren Hausdorffen espektroa

$$
\operatorname{hspec}^{\mathcal{G}}(G):=\left\{\operatorname{hdim}^{\mathcal{G}}(H) \mid H \leq G \text { itxia da }\right\} \subseteq[0,1]
$$

da.

Ohartu, Adibideak 4.3-ren ondorioz $\{0,1\} \subseteq \operatorname{hspec}^{\mathcal{G}}(G)$ dela. Ikus daitekeenez, $\mathcal{G}$-ri dagokion Hausdorffen espektroak, nolabait, $G$ talde profinituaren azpitalde itxien hedapena islatzen du. Testuinguru honetan, interesgarria da talde profinitu ezberdinek filtrazio serie ezberdinekiko izan ditzaketen Hausdorffen espektroak aztertzea. Are interesgarriagoa izango litzateke, gainera, $G$ talde baten Hausdorffen espektroak taldearen inguruan informazio estrukturala eman ahal izango baligu.

Azter dezagun adibide konkretu bat ideia honen harira. Pro- $p$ talde bat $p$-adiko analitikoa dela esaten da heina finitua badu, hau da, azpitalde itxien sortzaile kopurua bornatua badago (6. atalean talde profinitu $p$-adiko analitikoen beste definizio bat emango dugu, ikuspuntu analitikotik). Pro- $p$ talde $p$-adiko analitikoak finituki sortuak dira. Horrela, Adibideak 4.5-eko notazioa mantenduz, honako hau dugu:

Teorema 5.2 (ikusi [4, Korolarioa 1.2] eta [5, Proposizioa 1.5]). Izan bitez $G$ pro-p talde p-adiko analitikoa eta $\mathcal{G} \in\left\{\mathcal{P}, \mathcal{P}^{*}, \mathcal{F}, \mathcal{D}\right\}$ filtrazio seriea. Orduan, $\operatorname{hspec}^{\mathcal{G}}(G)$ finitua $d a$.

Emaitza hori aurrerago emango dugun Teorema 6.5-en korolario argia da. Adibideak 4.5-eko filtrazio serie gehienentzat balio badu ere, $\mathcal{L}$ filtrazio 
serierako frogatzea problema irekia da oraindik. Talde profinituen Hausdorffen dimentsioaren teorian, egungo problema ireki nagusia, ziur asko, emaitza horren alderantzizkoa frogatzea da, hau da:

Aierua 5.3. Izan bitez $G$ pro- $p$ talde finituki sortua eta $\mathcal{G} \in\left\{\mathcal{P}, \mathcal{P}^{*}, \mathcal{F}, \mathcal{L}\right.$, $\mathcal{D}\}$ filtrazio seriea. Demagun $\operatorname{hspec}^{\mathcal{G}}(G)$ finitua dela. Orduan, $G$ pro- $p$ talde $p$-adiko analitikoa da.

Aieru hori pro- $p$ talde ebazgarrietarako betetzen dela frogatzen da [5]-en. Gogoratu $G$ talde bat ebazgarria dela $G$-tik $\{1\}$-era doan serie subnormal beherakor bat existitzen bada, non ondoz ondoko zatidura guztiak abeldarrak diren. Pro- $p$ talde finituki sortu orokorrentzat, gainera, ondorengo emaitza estrukturala ere aurkezten da.

Teorema 5.4 (ikusi [4, Teorema 1.3] eta [5, Proposizioa 1.5]). Izan bedi $G$ pro-p talde finituki sortua eta $\mathcal{G} \in\left\{\mathcal{P}, \mathcal{P}^{*}, \mathcal{F}, \mathcal{D}\right\}$. Ondorengoak baliokideak dira:

(i) G pro-p talde p-adiko analitikoa da.

(ii) Edozein $H$ azpitalde infinitu itxik $\operatorname{hdim}^{\mathcal{G}}(H)>0$ betetzen $d u$.

Kontrako muturrean, Hausdorffen espektro infinitua duten taldeen adibide asko topa daitezke. Baina, posible al da (Adibideak 4.5-en definituriko filtrazio serie natural bat hartuta) pro- $p$ talde finituki sortu baten Hausdorffen espektroa $[0,1]$ tarte osoa izatea? Ondorengo adibideetan ikusiko dugun bezala, galdera honen erantzuna baiezkoa da. Ez dugu, ordea, gehiegi sakonduko adibide hauetan, bertan ematen diren emaitzak ez baitira berehalakoak.

Adibideak 5.5. (i) Izan bedi $\mathcal{G} \in\left\{\mathcal{P}, \mathcal{P}^{*}, \mathcal{F}, \mathcal{D}\right\}$ eta definitu $W=C_{p}\left\langle\mathbb{Z}_{p}\right.$, hau da, $p$ ordenako $C_{p}$ talde ziklikoaren eta $\mathbb{Z}_{p}$ zenbaki $p$-adikoen arteko koroa-biderkadura. Orduan, $\operatorname{hspec}^{\mathcal{G}}(W)=[0,1]$ eta

$$
\operatorname{hspec}^{\mathcal{L}}(W)=[0,1 / 2] \cup\left\{1 / 2+m / 2 p^{n} \mid n \in \mathbb{N}_{0}, 1 \leq m \leq p^{n}-1\right\} \cup\{1\}
$$

betetzen da (ikusi [6] eta [7, Korolarioa 2.11]).

(ii) Talde adarkatu profinitu guztien Hausdorffen espektroa $[0,1]$ tarte osoa da, egonkortzaileek definitzen duten filtrazioarekiko (ikusi [6]). Bereziki, sustraidun zuhaitzen automorfismoen taldearen espektroa ere $[0,1]$ da.

(iii) Izan bedi $F_{d}$ taldea $d>1$ sortzaileko pro- $p$ talde askea, hau da, $d$ sortzaileko talde askearen zatidura talde guztien alderantzizko limitea. Orduan,

$$
\operatorname{hspec}^{\mathcal{P}^{*}}\left(F_{d}\right)=\operatorname{hspec}^{\mathcal{F}}\left(F_{d}\right)=\operatorname{hspec}^{\mathcal{D}}\left(F_{d}\right)=[0,1]
$$

daukagu (ikusi [8, Teorema 1.4]). 
(iv) Izan bedi $G=\mathbb{F}_{p}[[t]]$ koefizienteak $p$ kardinaleko gorputz finituan dituen berretura serie formalen taldea batuketarekiko. Orduan, $\operatorname{hspec}^{\mathcal{G}}(G)=[0,1] \mathrm{da}$, non $\mathcal{G}$ kongruentzia azpitaldeen filtrazioa den (ikusi [4, Lemma 4.1]). Ohartu, hala ere, talde hori ez dela finituki sortua.

Hausdorffen espektroarekin egin den antzera, modu naturalean, azpitalde itxiak kontsideratu ordez, azpitalde itxi normalak kontsidera daitezke. Horrela, ondorengo hau defini dezakegu.

Definizioa 5.6. Izan bitez $G$ talde profinitua eta $\mathcal{G}$ filtrazio seriea. Orduan, $\mathcal{G}$ filtrazioari dagokion $G$-ren Hausdorffen espektro normala

$$
\operatorname{hspec}_{\unlhd} \mathcal{G}(G):=\left\{\operatorname{hdim}^{\mathcal{G}}(H) \mid H \unlhd G \text { itxia da }\right\}
$$

da.

Hala ere, Hausdorffen ohiko espektroarekin ez bezala, Hausdorffen espektro normal infinitua duten pro- $p$ talde finituki sortuen oso adibide gutxi ezagutzen dira. Aurreko adibideekin jarraituz:

Adibideak 5.7. (i) Izan bitez $\mathcal{G} \in\left\{\mathcal{P}, \mathcal{P}^{*}, \mathcal{F}, \mathcal{L}, \mathcal{D}\right\}$ eta $W=C_{p} \mid \mathbb{Z}_{p}$. Orduan, hspec $\mathcal{G}(W)=\{0,1\}$ dugu (ikusi [7, Korolarioa 2.8]).

(ii) Izan bedi $F_{d}$ taldea $d \geq 1$ sortzaileko pro- $p$ talde askea. Orduan,

$$
\operatorname{hspec}_{\unlhd}^{\mathcal{F}}\left(F_{d}\right)=\operatorname{hspec}_{\unlhd}^{\mathcal{D}}\left(F_{d}\right)=\{0,1\}
$$

betetzen da. Ohartu $d=1$ bada, orduan $F_{d}=\mathbb{Z}_{p}$ dela; eta, beraz, emaitza $\left\{\mathcal{P}, \mathcal{P}^{*}, \mathcal{F}, \mathcal{L}, \mathcal{D}\right\}$ filtrazio serie guztietarako betetzen dela.

(iii) Izan bedi $G=\mathbb{F}_{p}[[t]]$ taldea batuketarekiko. Talde hau abeldarra denez, haren azpitalde guztiak normalak dira. Beraz, $\mathcal{G}$ kongruentzia azpitaldeen filtrazioa bada,

$$
\operatorname{hspec}^{\mathcal{G}}(G)=\operatorname{hspec}_{\unlhd}^{\mathcal{G}}(G)=[0,1]
$$

dugu. Hala ere, lehenago esan bezala, talde hau ez da finituki sortua.

Gauzak horrela, [7]-n pro- $p$ talde finituki sortu bat eraikitzen da, non Adibideak 4.5-en definitutako filtrazio serie natural guztientzako Hausdorffen espektro normalak tarte infinitu bat baitu barnean. Lehen autoreak, Klopschek eta Thillaisundaramek, [7]-n oinarrituz, emaitza hori hobetzen dute honako teoreman honetan.

Teorema 5.8 (ikusi [9] eta [10]). Existitzen da 2 sortzaileko G pro-p talde bat, non

$$
\operatorname{hspec}_{\unlhd} \mathcal{G}(G)=[0,1]
$$

baita $\mathcal{G} \in\left\{\mathcal{P}, \mathcal{P}^{*}, \mathcal{F}, \mathcal{L}, \mathcal{D}\right\}$ guztietarako 
Modu horretan, [7]-ko Problema 1.2 (b), (c) eta [4]-ko Problema 5 ebazten dira (azken hau jada ebatzita zegoen $\mathcal{P}, \mathcal{F}$ eta $\mathcal{D}$ filtrazio serieentzat).

\section{HAUSDORFFEN DIMENTSIOA TALDE $R$-ANALITIKOETAN}

Hausdorffen dimentsioa hasiera batean kontzeptu geometrikoa da, multzo batek espazio metriko bat lokalki zenbat betetzen duen neurtzen baitu. Beraz, logikoa da egitura aljebraikoaz gain egitura geometrikoa ere baduten taldeak aztertzea. Azterketa horretarako lehen hautagaiak Lieren taldeak dira, hau da, lokalki gorputz lokal $-\mathbb{R}$ edo $\mathbb{Q}_{p}$, kasurako- baten gainean barietate analitikoak ere badiren talde abstraktuak, bi egitura horiek bateragarriak izanik (ikusi [11] gaian sakontzeko).

Dena den, Lieren talde errealak $\mathbb{R}^{n}$-ko ireki bati lokalki homeomorfoak direnez, ez dira talde profinituak, diskretuak izan ezean. Bestalde, Lieren talde $p$-adiko trinkoak arestian aipatutako pro- $p$ talde $p$-adiko analitikoak dira (ikusi [12, Interludioa A]), eta horietan Hausdorffen dimentsioaren inguruko teoria emankorra garatu da.

Lieren talde $p$-adikoetan baliokidea da barietate egitura $\mathbb{Q}_{p}$-n edo honen baluazio eraztunean, $\mathbb{Z}_{p}$ zenbaki $p$-adiko osoak, hartzea (ikusi [12, Adibideak 8.9(ii)]). Orobat, barietate egitura edozein eraztun topologiko metrizagarritan har daiteke; eta edozein $R$ integritate-domeinu noetherdarretan, $\mathfrak{a}$ ideal propio bat erabilita, metrika bat defini daiteke, $R^{n}$ espazio metriko egitura batez hornitzen duena (ikusi $[13,1$. gaia]). Topologia honi topologia a-adikoa deritzo. Izan ere, $x \in R^{n}$ puntuaren ingurune oinarria

$$
\mathcal{N}_{x}=\left\{x+\left(\mathfrak{a}^{* i}\right)^{n}\right\}_{i \in \mathbb{N}}
$$

da, non $\mathfrak{a}^{{ }^{*} i}$ berretura-ideala den. Integritate-domeinu noetherdarren artean propietate berezi batzuk dituztenak hartuko dira:

Definizioa 6.1. Pro-p domeinu bat $R$ integritate-domeinu noetherdar lokal bat da, non $\mathfrak{m}$ bada ideal maximal bakarra, orduan:

(i) $R / \mathfrak{m}$ zatidura-gorputza $p$ karakteristikadun gorputz finitua da.

(ii) $R$ osoa da topologia m-adikoarekin.

Ohartu $R$ pro- $p$ domeinua bada $(R,+)$ talde batukorra pro- $p$ taldea dela. Domeinu horien adibide nagusiak $\mathbb{Z}_{p}$ eta $\mathbb{F}_{p}[[t]]$ berretura serieen eraztuna dira.

Domeinu horiek erabilita barietate $R$-analitikoak defini daitezke, eta artikulu honetan $[12,13$. gaia]-ri jarraituko gatzaizkio horretarako. Lehe- 
nengo funtzio $R$-analitikoak definitu behar dira, hau da, lokalki $R$-ren gaineko berretura serie konbergenteak diren funtzioak.

Oharra. Izan bedi $R$ pro- $p$ domeinua. Definitu $\Lambda_{0}\left[\left[X_{1}, \ldots, X_{d}\right]\right]$ eraztuna honako modu honetan: $R$ ideal nagusietako domeinua ez denean $\Lambda_{0}\left[\left[X_{1}, \ldots, X_{d}\right]\right]:=R\left[\left[X_{1}, \ldots, X_{d}\right]\right]$ da eta $R$ ideal nagusietako domeinua denean, $R$-ren zatikien gorputza $K$ eta $\mathfrak{m}=(\gamma)$ badira, orduan $\Lambda_{0}\left[\left[X_{1}, \ldots, X_{d}\right]\right]$

$\left\{\sum_{\alpha \in \mathbb{N}_{0}^{d}} a_{\alpha} X_{1}^{\alpha_{1}} \ldots X_{d}^{\alpha_{d}} \in K\left[\left[X_{1}, \ldots, X_{d}\right]\right] \mid \exists N \geq 0, a_{\alpha} \gamma^{N\left(\alpha_{1}+\cdots+\alpha_{d}\right)} \in R \forall \alpha \in \mathbb{N}_{0}^{d} \backslash\{0\}\right\}$

eraztuna da. Ohartu $\Lambda_{0}\left[\left[X_{1}, \ldots, X_{d}\right]\right]$-ko berretura serieak $N \in \mathbb{N}$-ren batentzat topologia $\mathfrak{m}$-adikoarekiko konbergenteak direla $\left(\mathfrak{m}^{* N}\right)^{d}$-n.

Definizioa 6.2. Izan bitez $R$ pro- $p$ domeinua eta $U \subseteq R^{n}$ irekia. Orduan, $f: U \rightarrow R$ funtzio $R$-analitikoa dela esaten da, $y \in U$ bakoitzerako existitzen direnean $N \in \mathbb{N}$ zenbaki arrunta eta $F \in \Lambda_{0}\left[\left[X_{1}, \ldots, X_{n}\right]\right]$ berretura seriea, non

(i) $y+\left(\mathfrak{m}^{* N}\right)^{n} \subseteq U$ eta

(ii) $F(x)=f(y+x)$ den $x \in\left(\mathfrak{m}^{*}\right)^{n}$ guztietarako.

Halaber, $f=\left(f_{1}, \ldots, f_{m}\right): U \rightarrow R^{m}$ funtzio $R$-analitikoa da, $f_{i} R$-analitikoa denean $i \in\{1, \ldots, m\}$ guztietarako.

Ikus daiteke funtzio $R$-analitikoak bereziki jarraituak direla (ikusi [12, Lema 13.3]).

Definizioa 6.3. Izan bitez $R$ pro- $p$ domeinua eta $M$ espazio topologikoa. Orduan,

(i) $M$-ren karta $R$-analitiko bat $(U, \phi, n)$ hirukote bat da, non $n \in \mathbb{N}_{0}$ kartaren dimentsioa den; $U \subseteq M$ ireki ez-hutsa den eta $\phi: U \rightarrow \phi(U) \subseteq R^{n}$ homeomorfismoa den, $\phi(U)$-ri $R^{n}$-ko azpiespazio topologia esleituz.

(ii) $M$-ren atlas bat $\mathcal{A}=\left\{\left(U_{i}, \phi_{i}, n_{i}\right)\right\}_{i \in I} M$-ren karta $R$-analitiko bilduma bat da, non $M=\cup_{i \in I} U_{i}$ eta edozein $i, j \in I$-rako,

$$
\left.\phi_{i} \circ \phi_{j}^{-1}\right|_{\phi_{j}\left(U_{i} \cap U_{j}\right)}: \phi_{j}\left(U_{i} \cap U_{j}\right) \rightarrow R^{n_{i}}
$$

eta

$$
\left.\phi_{j} \circ \phi_{i}^{-1}\right|_{\phi_{i}\left(U_{i} \cap U_{j}\right)}: \phi_{i}\left(U_{i} \cap U_{j}\right) \rightarrow R^{n_{j}}
$$

koordenatu aldaketa funtzioak, funtzio $R$-analitikoak diren. 
Bi atlas, $\mathcal{A}$ eta $\mathcal{B}$, bateragarriak dira $\mathcal{A} \cup \mathcal{B}$ ere $M$-ren atlas bat denean. Horrela, atlas maximal bat beste edozein atlas bateragarri parte duen atlas bat da.

Horrenbestez, barietate $R$-analitiko bat atlas maximal bat duen $M$ espazio topologikoa da. Halaber, kartek emandako egitura lokalaz baliatuz, Definizioa 6.2-ko espiritu berarekin, barietateen arteko funtzio $R$-analitikoak defini daitezke:

Definizioa 6.4. Izan bitez $M$ eta $N$ barietate $R$-analitikoak eta $f: M \rightarrow N$ funtzioa. Orduan, $f$ funtzio $R$-analitikoa da $x \in M$ puntuan, baldin eta existitzen badira $x$-ren $(U, \phi, n)$ karta $M$-n eta $f(x)$-ren $(V, \psi, m)$ karta $N$-n, non $f^{-1}(V)$ irekia den $M$-n eta

$$
\left.\psi \circ f \circ \phi^{-1}\right|_{\phi\left(U \cap f^{-1}(V)\right)}: \phi\left(U \cap f^{-1}(V)\right) \rightarrow R^{m}
$$

funtzioa $R$-analitikoa den. Modu honetan, $f$ funtzioa $R$-analitikoa da $M$-ko puntu guztietan $R$-analitikoa denean.

Horrela, $G$ talde $R$-analitiko bat barietate $R$-analitikoa ere baden talde abstraktu bat da, bi egitura horiek bateragarriak izanik. Hau da,

(i) $m: G \times G \rightarrow G$ non $m(g, h)=g \cdot h$ biderketa eta

(ii) $\iota: G \rightarrow G$ non $\iota(g)=g^{-1}$ alderantzizkoa

funtzio $R$-analitikoak dira. Bestalde, talde hauetan, karten dimentsioa erabilita, puntu bakoitzaren inguruan naturalki dimentsio topologiko bat definitzea dago, zenbaki osoa izango dena. Izan ere, $\left(U_{i}, \phi_{i}, n_{i}\right)(i=1,2)$ bi karta emanda, ikus daiteke $U_{1} \cap U_{2} \neq \varnothing$ bada, orduan $n_{1}=n_{2}$ dela (ikusi [12, Lema 13.11]). Horrenbestez, barietate $R$-analitiko baten dimentsioa, $\operatorname{dim} G$ denotatuko duguna, identitatea barruan duen edozein $(U, \phi, n)$ kartaren $n$ zenbakia da.

Sarreran aipatu bezala, espazio euklidear errealetan azpibarietateen, kurba edo gainazal leunak kasurako, Hausdorffen dimentsioa eta barietate dimentsioa - dimentsio topologiko lokala - bat datoz. Talde $R$-analitikoetan antzeko zerbait gertatzen da azpibarietateak ere badiren azpitaldeetako. Azpibarietatea izateak, [11, Atala 3.11]-ko definizioari jarraituz, esan nahi du $x \in H$ bakoitzerako existitzen direla $U_{x} \subseteq H$ irekia, $x$ barruan duen $G$-ko $\left(V_{x}, \phi_{x}, n_{x}\right)$ karta eta $E_{x} \subseteq K^{d} K$-azpiespazio bektoriala ( $K R$-ren zatikien gorputza da), non

(i) $U_{x} \subseteq V_{x}$ eta

(ii) $\phi_{x}\left(U_{x}\right)=\phi_{x}\left(V_{x}\right) \cap E_{x}$ diren.

Azpitalde horiei, aldi berean azpitaldeak eta azpibarietateak direnak, azpitalde $R$-analitiko deritze. 
Talde $R$-analitiko trinkoak oinarri zenbakigarriko talde profinituak direnez ([12, Proposizioa 13.22]-tik ondoriozta daiteke), filtrazio serie normaletarako euren Hausdorffen dimentsioa (1) identitatea erabilita kalkula daiteke. Bereziki, talde $\mathbb{Z}_{p}$-analitiko trinkoen familia, hain zuzen ere, pro- $p$ talde $p$-adiko analitikoen familia da.

Teorema 6.5 (ikusi [4, Teorema 1.1] eta [5, Proposizioa 1.5]). Izan bitez $G$ pro-p talde p-adiko analitikoa eta $G \in\left\{\mathcal{P}, \mathcal{P}^{*}, \mathcal{F}, \mathcal{D}\right\}$ filtrazio seriea . Orduan, edozein $H \leq G$ azpitalde p-adiko analitikotarako

$$
\operatorname{hdim}^{\mathcal{G}}(H)=\frac{\operatorname{dim} H}{\operatorname{dim} G}
$$

$d a$.

Alde batetik, $G$ pro- $p$ talde $p$-adiko analitiko baten azpitalde itxiak $p$ adiko analitikoak direnez (ikusi [12, Teorema 9.6]), Teorema 5.2 berehala ondorioztatzen da emaitza horretatik,

$$
\operatorname{hspec}^{\mathcal{G}}(G) \subseteq\left\{0, \frac{1}{\operatorname{dim} G}, \ldots, \frac{\operatorname{dim}(G)-1}{\operatorname{dim} G}, 1\right\}
$$

baita. Bestalde, horrek erakusten duen moduan, azpitalde $p$-adiko analitikoen Hausdorffen dimentsioa oro har ez da osoa, baina talde profinitu orotan Hausdorffen dimentsioak $[0,1]$ tartean hartzen ditu balioak; beraz, $\operatorname{dim} G$ edozein delarik ere, Hausdorffen dimentsioaren balio oso posible bakarrak 0 eta 1 dira. Horregatik, talde $R$-analitiko profinitu batean, batzuetan hobe da hurrengo Hausdorffen dimentsio normalizatua hartzea. Hau da, edozein $H \leq G$ azpitalde itxitarako

$$
\widetilde{\operatorname{hdim}}^{\mathcal{G}}(H):=\operatorname{hdim}^{\mathcal{G}}(H) \cdot \operatorname{dim} G
$$

da, zeinak balioak $[0, \operatorname{dim} G]$ tartean hartzen dituen. Horrela, Teorema 6.5 honela geratzen da:

Korolarioa 6.6. Izan bitez $G$ pro-p talde p-adiko analitikoa eta $\mathcal{G} \in\left\{\mathcal{P}, \mathcal{P}^{*}, \mathcal{F}, \mathcal{D}\right\}$ filtrazio seriea. Orduan, edozein $H \leq G$ azpitalde $p$-adiko analitikotarako

$$
\widehat{\operatorname{hdim}}^{\mathcal{G}}(H)=\operatorname{dim} H
$$

$d a$.

Hots, pro- $p$ talde $p$-adiko analitikoetan, filtrazio natural askorekiko, dimentsio topologiko lokala - barietate dimentsioa - eta dimentsio fraktala - Hausdorffen dimentsio normalizatua - bat datoz. 
Hala ere, ba al dago pro- $p$ talde $p$-adiko analitikoetan dimentsio fraktal ez-osoa duen azpitalde itxirik? Erantzuna ezezkoa da, adesara aipatu denez, jakina baita azpitalde itxi guztiak azpitalde $p$-adiko analitikoak direla, eta, ondorioz, denek Hausdorffen dimentsio normalizatu osoa dute. Hau da, espazio metriko horietan ez dago «azpitalde fraktalik».

Dena den, pro- $p$ domeinu orokorragoak hartuz gero, dimentsio fraktal ez-osoa duten azpitaldeak topa daitezke. Haatik, talde $R$-analitiko profinitu orokor bat emanda lehenengo arazoa ezinbestean finituki sortua ez izatea da. Beraz, ezin dira Adibideak 4.5-eko filtrazio serieak erabili, esan bezala gerta baitaiteke bertako azpitaldeak irekiak ez izatea.

Horrenbestez, lehenik eta behin, talde $R$-analitiko profinituetan filtrazio serie egoki bat bilatu behar da. Horretarako, talde $R$-analitikoen familia berezi bat aurkeztuko dugu.

Definizioa 6.7. Izan bedi $S$ talde $R$-analitikoa. Orduan, $S$ taldea $N$ mailako eta $d$ dimentsioko talde $R$-estandarra dela esaten dugu $(S, \phi, d)$ atlas global bat existitzen denean, non

(i) $\phi: S \rightarrow\left(\mathfrak{m}^{*}\right)^{d}$ homeomorfismoa den,

(ii) $\phi(1)=0$ den eta

(iii) $j \in\{1, \ldots, d\}$ guztietarako existitzen den $F_{j} \in R\left[\left[X_{1}, \ldots, X_{2 d}\right]\right]$, koefizienteak $R$-n dituen gai askerik gabeko berretura serie formala, non

$$
\phi(x y)=\left(F_{1}(\phi(x), \phi(y)), \ldots, F_{d}(\phi(x), \phi(y))\right)
$$

den $x, y \in S$ guztietarako.

Askotan, talde $R$-estandarrak $(S, \phi)$ moduan denotatu ohi dira, homeomorfismoa azpimarratzeko.

Ikus daiteke $G$ talde $R$-analitiko guztiek daukatela azpitalde ireki, eta, beraz, dimentsio bereko $R$-estandar bat (ikusi [12, Teorema 13.20]), deitu $(S, \phi)$. Horrela, azpitalde hori erabilita, talde $R$-analitiko batean $\mathcal{S}=\left(S_{n}\right)_{n \geq 0}$ filtrazio serie R-estandarra defini daiteke, modu honetan:

$$
S_{n}:=\phi^{-1}\left(\left(\mathfrak{m}^{*(N+n)}\right)^{d}\right),
$$

non $N$ zenbaki arrunta $(S, \phi)$-ren maila eta $d=\operatorname{dim} S=\operatorname{dim} G$ diren. Erraz ikusten da serie horrek benetan filtrazio serie (agian ez normala) izateko beharrezko baldintzak betetzen dituela.

Hala ere, $G$ talde $R$-analitiko batek azpitalde ireki $R$-estandar bat baino gehiago izan ditzake, eta bakoitzak filtrazio serie $R$-estandar bat definitzen 
du. Aitzitik, filtrazio serie horiek guztiek Hausdorffen dimentsio bera definitzen dute.

Teorema 6.8 (ikusi [14, Teorema 3.1]). Izan bitez $G$ talde $R$-analitiko trinkoa eta $(S, \phi)$ eta $(T, \psi)$ bi azpitalde $R$-estandar ireki. Deitu $\mathcal{S}=\left(S_{n}\right)_{n \geq 0}$ eta $\mathcal{T}=\left(T_{n}\right)_{n \geq 0}$, hurrenez hurren, $(S, \phi)$ eta $(T, \psi)$ azpitaldeen bidez definitutako filtrazio serie R-estandarrei. Orduan, edozein $H \leq G$ azpitalde itxitarako

$$
\operatorname{hdim}^{\mathcal{S}}(H)=\operatorname{hdim}^{\mathcal{T}}(H)
$$

$d a$.

Beraz, filtrazio serie $R$-estandarrak erabilita, talde $R$-analitikoetan taldearen barietate egitura kontuan hartzen duen Hausdorffen dimentsio natural bat defini daiteke, Hausdorffen dimentsio R-estandarra deituko duguna eta hdim st denotatuko dena. Hau da, $\operatorname{hdim}_{\text {st }}=\operatorname{hdim}^{\mathcal{S}}$ da, $\mathcal{S}$ edozein filtrazio serie $R$-estandar izanik. Modu berean, Hausdorffen dimentsio $R$-estandar normalizatua, $\widehat{\text { hdim }}_{\mathrm{st}}$, defini daiteke.

Filtrazio horrekiko Korolarioa 6.6-ren emaitza analogoa dago. Hau da, talde $R$-analitiko profinituen azpitalde $R$-analitikoek dimentsio topologiko lokalarekin bat datorren dimentsio fraktal osoa dute.

Teorema 6.9 (ikusi [14, Teorema Nagusia]). Izan bedi G talde R-analitiko trinkoa. Orduan, edozein $H \leq G$ azpitalde $R$-analitikotarako

$$
\widetilde{\operatorname{hdim}}_{\mathrm{st}}(H)=\operatorname{dim} H
$$

$d a$.

Talde $R$-analitiko orokor hauetan, ordea, azpitalde itxi guztiak ez dira zuzenean azpitalde $R$-analitikoak. Esate baterako, $G=\left(\mathbb{F}_{p}[[t]],+\right)$ talde $\mathbb{F}_{p}[[t]]$-analitiko batukorra hartuta, $\mathbb{F}_{p}\left[\left[t^{2}\right]\right]$ azpitalde itxia da, eta bere kabuz talde $\mathbb{F}_{p}[[t]]$-analitiko egitura naturala du. Baina, ez da $G$-ren azpibarietatea, eta, beraz, ezta azpitalde $\mathbb{F}_{p}[[t]]$-analitikoa ere.

Horrenbestez, talde $R$-analitiko trinkoetan badaude «azpitalde fraktala» izateko hautagaiak, azpitalde itxi ez $R$-analitikoak, alegia. Are gehiago, bigarren autorearen eta González-Sánchezen emaitza honek erakusten duen moduan, zenbait talde $R$-analitikotan posible da Hausdorffen espektro $R$-estandar normalizatua,

$$
\widetilde{\operatorname{hspec}}_{\mathrm{st}}(G):=\left\{\widetilde{\operatorname{hdim}}_{\mathrm{st}}(H) \mid H \leq G \text { azpitalde itxia da }\right\},
$$

guztiz deskribatzea. 
Teorema 6.10 (ikusi $[15])$. Izan bedi G talde $\mathbb{F}_{p}[[t]]$-analitiko trinko ebazgarria. Orduan,

$$
\widetilde{\operatorname{hspec}}_{\mathrm{st}}(G)=[0, \operatorname{dim} G]
$$

da.

Horrenbestez, ondoriozta daiteke, talde $p$-adikoetan ez bezala, talde $\mathbb{F}_{p}[[t]]$-analitiko trinko ebazgarrietan barietate $\mathbb{F}_{p}[[t]]$-analitikoak ez diren azpitalde itxiak badaudela. Bestetik, taldea ebazgarria izateko baldintza kentzen badugu, emaitza partziala lor dezakegu.

Teorema 6.11 (ikusi [15]). Izan bedi $G$ talde $\mathbb{F}_{p}[[t]]$-analitiko trinkoa. Orduan, edozein $\eta \in[0,1]$-tarako existitzen da $H_{\eta} \leq G$ azpitalde itxia, non $\widehat{\operatorname{hdim}}_{\mathrm{st}}\left(H_{\eta}\right)=\eta$ den.

Berriro ere, badaude Hausdorffen dimentsio ez-osoko azpitaldeak, baina agian $[0, \operatorname{dim} G]$ tarteko zenbait baliotarako ez dago dimentsio fraktal hori duen azpitalderik. Are gehiago, badaude talde $\mathbb{F}_{p}[[t]]$-analitiko trinkoak, zeinek ez daukaten dimentsio fraktal altuko azpitalderik. Adibidez, hartu

$$
\mathrm{SL}_{n}\left(\mathbb{F}_{p}[[t]]\right)=\left\{A \in \operatorname{Mat}_{n}\left(\mathbb{F}_{p}[[t]]\right) \mid \operatorname{det} A=1\right\}
$$

matrize talde berezi lineala, hau da, $n^{2}-1$ dimentsioko talde $\mathbb{F}_{p}[[t]]$-analitiko trinkoa.

Teorema 6.12 (ikusi [4, Teorema 1.4]). Izan bitez $n$ zenbaki arrunta eta $\eta \in\left(n^{2}-n, n^{2}-1\right)$, orduan, ez da existitzen $\overline{\mathrm{hdim}}_{\mathrm{st}}\left(H_{\eta}\right)=\eta$ betetzen duen $H_{\eta} \leq \mathrm{SL}_{n}\left(\mathbb{F}_{p}[[t]]\right)$ azpitalde itxirik.

\section{ESKER ONAK}

Bi autoreek Espainiako Gobernuko MTM2017-86802-P proiektuaren eta Eusko Jaurlaritzako IT974-16 proiektuaren babesa dute. Era berean, lehenengo autoreak Euskal Herriko Unibertsitatearen doktoratu aurreko bekaren laguntza jaso du eta bigarrenak Zientzia, Berrikuntza eta Unibertsitateak Ministerioaren babesa, FPU17/04822 doktoratu aurreko laguntzaren bidez. Espainiako Gobernuaren diru-laguntzen zati bat EGEFk finantzatzen du.

\section{BIBLIOGRAFIA}

[1] FALCONER, K. 1990. Fractal geometry: mathematical foundations and applications, John Wiley and Sons, New York.

[2] FOLLAND, G.B. 1999. Real Analysis: Modern Techniques and Their Applications, John Wiley and Sons, New York. 
[3] ABERCROMBIE, A.G. 1994. «Subgroups and subrings of profinite rings». Math. Proc. Cambridge Philos. Soc., 116, 209-222.

[4] BARNEA, Y. eta SHALEV, A. 1997. «Hausdorff dimension, pro-p groups and Kac-Moody algebras». Trans. Amer. Math. Soc., 349, 5073-5091.

[5] KLOPSCH, B., THILLAISUNDARAM, A. eta ZUGADI-REIZABAL, A. 2019. «Hausdorff dimension in $p$-adic analytic groups», Israel J. Math., 231, 1-23.

[6] KLOPSCH, B. 1999. Substitution Groups, Subgroup Growth and Other Topics (Doktoretza tesia), University of Oxford, Oxford.

[7] KLOPSCH, B. eta THILLAISUNDARAM, A. 2019. «A pro- $p$ group with infinite normal Hausdorff spectra». Pacific. J. Math., 303, 569-603.

[8] GARAIALDE, O., GARRIDO, A. eta KLOPSCH, B. 2019. «Pro- $p$ groups of positive rank gradient and Hausdorff dimension». J. London Math. Soc., 101, 1008-1040.

[9] DE LAS HERAS, I. eta KLOPSCH, B. 2021. «A pro- $p$ group with full normal Hausdorff spectra». Math. Nachr., argitaratzeko.

[10] DE LAS HERAS, I. eta THILLAISUNDARAM, A. 2021. «A pro-2 group with full normal Hausdorff spectra». arXiv: 2102.02117.

[11] SERRE, J.P. 1992. Lie Algebras and Lie Groups, Springer-Verlag, BerlinHeidelberg.

[12] DIXON, J., DU SAUTOY, M., MANN, A. eta SEGAL, D. 1999. Analytic Pro-p Groups, Cambridge University Press, Cambridge.

[13] GRECO, S. eta SALMON, P. 1971. Topics in m-adic Topologies, SpringerVerlag, New York-Heidelberg-Berlin.

[14] FERNÁNDEZ-ALCOBER, G.A., GIANNELLI, E. eta GONZÁLEZ-SÁNCHEZ, J. 2017. «Hausdorff dimension in $R$-analytic profinite groups», $J$. Group Theory, 20, 579-587.

[15] GONZÁLEZ-SÁNCHEZ J. eta ZOZAYA A. 2021. «Standard Hausdorff spectrum of compact $\mathbb{F}_{p}[[t]]$-analytic groups», Monatsh. Math, 195, 401-419. 